\title{
Synthesis of Prenyl Alcohol from Isoprene
}

\author{
Xiaofei Jiang ${ }^{1, a}$, Ying Zhang ${ }^{1}$, Yunzheng $\mathrm{Li}^{2}$, Qingshan Zhang ${ }^{1}$ and \\ Hongquan Yin* ${ }^{1, b}$
}

\author{
${ }^{1}$ Schoolof Chemical Engineering and Environment, BeijingInstitute of Technology, Beijing 100081 , \\ China; \\ ${ }^{2}$ Nanjing Guohai Bio-tech Co. Ltd, Nanjing 211500, China. \\ a15201609387@163.com, bhqyin77@sohu.com
}

\begin{abstract}
Keywords: Isoprene; Chlorination; Esterification; Saponification; Prenyl Alcohol
\end{abstract} (3-methyl-2-buten-1-ol).

Abstract:One method for synthesis of prenyl alcohol starting from isoprene was developed. Isoprene was chlorinated by concentrated hydrochloric acid, then esterification and saponification were occurring until prenyl alcohol was prepared. Some key influencing factors including reaction temperature,reaction time and molar ratio of reactants were studied. Through experimental research, the best reaction conditions were confirmed. Under the best conditions, total yield of prenyl alcohol from isoprene reached 84.39 \%.The structure and purity of prenyl alcohol wascharacterized by IR, ${ }^{1} \mathrm{H}-\mathrm{NMR}$ and GC.This synthesis processing had the advantages of easily available raw materials, simple operation and purely products, which would have widely prospects for industrial development. The chemical equation was shown in (1):

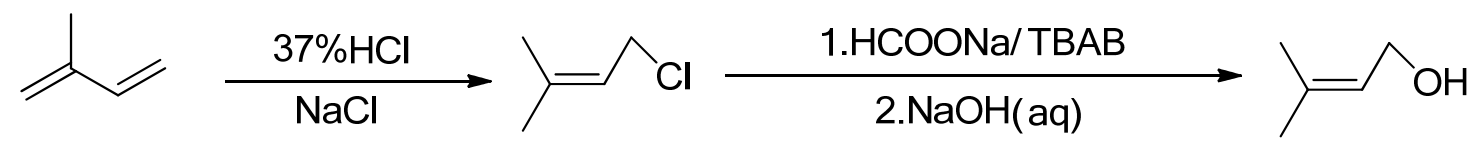

\section{Introduction}

Prenyl alcohol is an important intermediate in synthesis of manyfood additives, medicines and pesticides $^{[1,2]}$, such as citral, insecticide of permethrin and so on. Among them, citral is widely used in various fields and demands exceeds supply ${ }^{[3]}$ every year.Citral is one kind of food flavor which our laws allow to use, it can be used directly in soft drink, ice cream, candy, baking food and so on. In medical field, researchers find that citral has good biological insecticidal activity, antibacterial effect and anti-oxidative capability ${ }^{[4,5]}$. At the same time, citral has positive effect of treatment of angiocardiopathy, leukaemia ${ }^{[6]}$ and also has anti-allergic effect, anti-asthmatic and antitussive effect $^{[7]}$.

In recent years, researchers found that isoprene could be used to prepare prenyl alcohol. Preparation of prenyl alcohol from isoprene will be a promising route, because isoprene is mainly got from tail gas of oil cracking and it is cheap and easily available. On the basis of previous studies $^{[8,9]}$, sodium chloride and glacial acetic acid were drew into the production process of prenyl alcohol. We optimized the process and got a higher yield and selectivity.

\section{Experimental}

Chlorination of Isoprene: Isoprene $(10 \mathrm{~mL}, 0.1 \mathrm{~mol})$, cuprous chloride $(0.3 \mathrm{~g})$, glacial acetic acid(1mL) and sodium chloride solid(2.4 g, $0.04 \mathrm{~mol})$ were introduced into a round-bottom flask(50 $\mathrm{mL}$ ) fitted with a constant pressure funnel and a thermometer. The flask was placedin an ice-water bath. Then concentrated hydrochloric acid $(37 \%, \mathrm{~m} / \mathrm{m})$ was added into the mixture drop by drop through the constant pressure funnel, kept the temperature at $10{ }^{\circ}$ Cand stirred for 2-3 hours. Then the temperature was increased to $20-25^{\circ}$ Cand continuedtoreact for 4 hours. The liquid mixture was washed three times with saturated salt water $(15 \mathrm{~mL} * 3)$, the oil phase was collected and dried with anhydrous magnesium sulfate, filtered and evaporated.

Esterification and Saponification: The crude product of prenyl chloride was put into a 
round-bottom flask $(100 \mathrm{~mL})$ fitted with a reflux condensing tube and a thermometer. Toluene (20 $\mathrm{mL}$ ), anhydrous sodium formateand tetrabutyl ammonium bromidewere added into the flask. Temperature of oil bath was increased to $130{ }^{\circ} \mathrm{C}$, kept stirring for 2-3 hours. The mixturewas cooled to room temperature, hydroxide sodium solution $(30 \mathrm{~mL})$ was added into the flask and continued to react for $1-2$ hours at $100{ }^{\circ} \mathrm{C}$. Then the mixturewas allowed to separate into layers. The organic phase was collected, distilled under ordinary pressure and distillates of $140{ }^{\circ} \mathrm{C}$ were collected. The product was prenyl alcohol and product weight was8.1 gunder optimal conditions (theoretical weight was $8.6 \mathrm{~g})$.

\section{Results and discussion}

1. Specific impact of chlorination temperature to the yield of prenyl alcohol was shown in table 1.

Table 1. Impact of chlorinaton temperature to yield of prenyl alcohol.

\begin{tabular}{ccc}
\hline \multicolumn{2}{c}{ Temperature $/{ }^{\circ} \mathrm{C}$} & yield $/ \%$ \\
10 & 5 & 83.96 \\
& & 84.15 \\
& 15 & 78.85 \\
& 20 & 52.25 \\
\hline
\end{tabular}

As can be seen from table 1 , optimal chlorination temperature was $10{ }^{\circ} \mathrm{C}$ and yield of prenyl alcohol wasreduced as the temperature rose over $10{ }^{\circ} \mathrm{C}$. Theoretically at higher temperatures, self-polymerization was easy to occur which could reduce yield of prenyl alcohol.

2. Specific impact of sodium chloride to chlorination reaction was shown in table 2.

Table 2. Impact of sodium chloride to yield of prenyl alcohol.

\begin{tabular}{|c|c|c|c|}
\hline $\mathrm{NaCl}(\mathrm{s}) / \mathrm{g}$ & $\mathrm{HCl} / \mathrm{mL}(37 \%)$ & $\mathrm{n}$ (isoprene) : n ( $\mathrm{HCl})$ & yield/\% \\
\hline 0 & 20 & $1: 2.4$ & 42.33 \\
\hline 1.2 & 20 & $1: 2.4$ & 64.36 \\
\hline 2.0 & 20 & $1: 2.4$ & 68.59 \\
\hline 2.4 & 20 & $1: 2.4$ & 70.68 \\
\hline 1.2 & 30 & 1:3.6 & 76.62 \\
\hline 2.4 & 30 & 1:3.6 & 78.88 \\
\hline 3.0 & 30 & 1:3.6 & 78.16 \\
\hline
\end{tabular}

The addition of sodium chloride was to keep the concentration of hydrochloric acid at a relatively higher level. As we can see from table 2, when molar ratio of isoprene and hydrogen chloride was 1:2.4, yield of prenyl alcohol kept rising as continuous adding of sodium chloride, and when molar ratio of isoprene and hydrogen chloride was 1:3.6, weight of sodium chloride was $2.4 \mathrm{~g}$, the yield was the best at the same condition. So optimal molar ratio of isoprene and hydrogen chloride was 1:3.6, weight of sodium chloride was $2.4 \mathrm{~g}$.

3. Impact of chlorination reaction time to yield could be seen in table 3 .

Table 3. Impact of chlorination time to yield of prenyl alcohol.

$\begin{array}{ccl} & \text { Time/h } & \text { yield/\% } \\ & 2 & 66.15 \\ & 4 & 78.42 \\ 6 & & 84.39 \\ 8 & & 82.54\end{array}$

The data from table 3 showed that yield of prenyl alcohol increased as time went by, but it reduced when reaction time was over 6 hours. So the optimal chlorination time was 6 hours. 
4. Impact of sodium formate to esterifying was shown in table 4 .

Table 4. Impact of amount of esterifying agent to yield.

\begin{tabular}{|c|c|c|c|}
\hline \multirow{4}{*}{$\begin{array}{l}\mathrm{T} /{ }^{\circ} \mathrm{C} \\
130\end{array}$} & sodium formate/g & $\mathrm{N}$ (isoprene) : n (sodium formate) & yield/\% \\
\hline & 5 & $1: 0.75$ & 60.25 \\
\hline & 10 & \multirow[b]{2}{*}{$1: 2.25$} & 84.32 \\
\hline & 15 & & 84.14 \\
\hline
\end{tabular}

From table 4, we could see that yield of prenyl alcohol reached84.32 \%when the molar ration of isoprene and sodium formate was increased to 1:1.5. The yield changed little when continuing to add sodium formate. So optimal molar ratio of isoprene and sodium formate was 1:1.5.

5. Impact of concentration of sodium hydroxide solution to saponification was shown in table 5 .

Table 5. Impact of amount of saponification agent to yield.

\begin{tabular}{lcccc}
$\mathrm{T} /{ }^{\circ} \mathrm{C}$ & $\mathrm{NaOH} / \mathrm{g}$ & & $\mathrm{n}$ (isoprene) $: \mathrm{n}(\mathrm{NaOH})$ & yield/\% \\
100 & 4 & $1: 1$ & & 40.64 \\
& 5 & & $1: 1.25$ & 68.47 \\
& 6 & & $1: 1.5$ & 83.33 \\
& 7 & $1: 1.75$ & & 82.19 \\
\hline
\end{tabular}

We could see from table 5 that optimum molar ratio of isoprene and hydroxide was 1:1.5, corresponding mass percent concentration of sodium hydroxide solution was $20 \%(\mathrm{~m} / \mathrm{m})$. Yield of prenyl alcohol increased before the molar ratio reached1:1.5 and after that point yield reduced as the molar ratio continued to increase, the reason maybe that larger alkalinity brought more side effects.

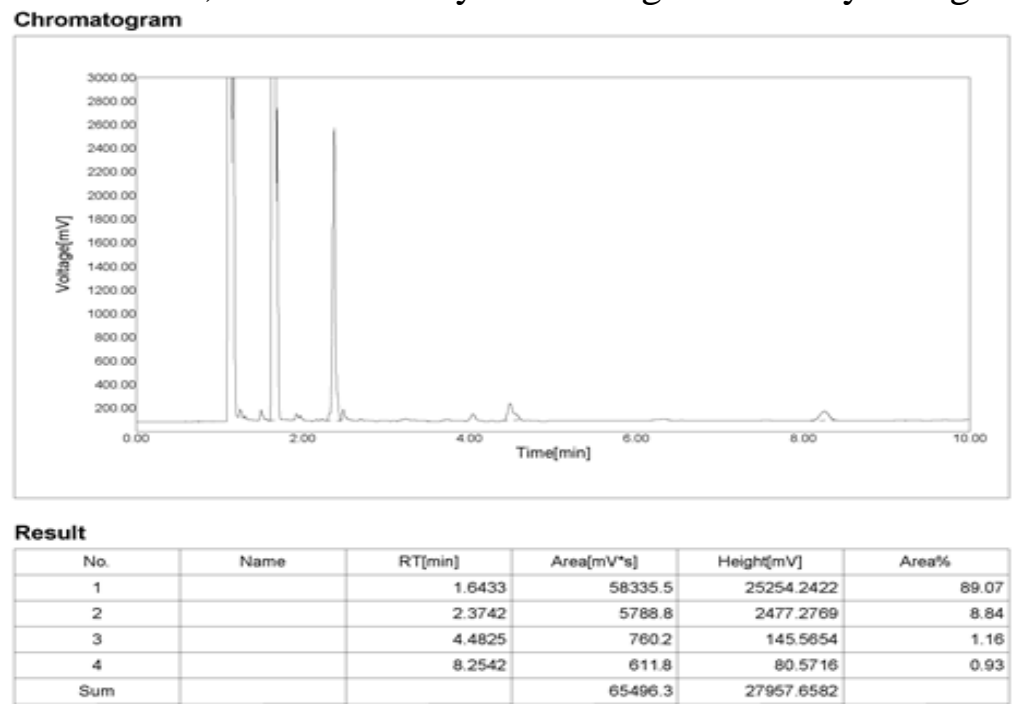

Fig. 1 GC of prenyl alcohol

Analysis of the reaction product showed that the purity of prenyl alcohol was $89.07 \%$ (GC, as shown in figure 1) and the yield of prenyl alcohol was $84.39 \%$ from isoprene which indicated that the reaction had a high yield and selectivity.The structure of prenyl alcohol was determined by IR and ${ }^{1} \mathrm{H}-\mathrm{NMR}$. IR (KBr) $\mathrm{cm}^{-1} 3317,2968,2929,2870,1674,1447,1378,1240,1037,1005$; ${ }^{1} \mathrm{H}-\mathrm{NMR}\left(400 \mathrm{MHz}, \mathrm{CDCl}_{3}\right) \delta 5.41(1 \mathrm{H}, \mathrm{t}, J=7.1 \mathrm{~Hz}), 4.13(2 \mathrm{H}, \mathrm{d}, J=7.1 \mathrm{~Hz}), 1.75(3 \mathrm{H}, \mathrm{s}), 1.69$ $(3 \mathrm{H}, \mathrm{s})$.

\section{Conclusions}

Optimization conditions of chlorination reaction: The molar ratio of isoprene and hydrogen chloride was 1:3.6. Quality percentage of glacial acetic acid which acted as co-solvent was $10 \%$. Quality percentage of cuprous chloride, the catalyst, was $4 \%$. Reaction time was 2.5 hours, temperature was $10{ }^{\circ} \mathrm{C}$. Transposition temperature was $20-25{ }^{\circ} \mathrm{C}$ and reaction time was 6 hours.

Optimization conditions of esterification: The molar ratio of isoprene and anhydrous sodium formate was 1:1.5, the molar ratio of isoprene and tetrabutyl ammonium bromide was 1:0.01. The reaction temperature was $130{ }^{\circ}$ Cand reaction time was 3 hours.

Optimization conditions of saponification: The molar ratio of isoprene and sodium hydroxide 
was 1:1.5. Mass concentration of sodium hydroxide solution was 20 30\%. The temperature was $100{ }^{\circ} \mathrm{C}$ and reaction time was 1.5 hours.

The structure of prenyl alcohol was determined by IR and ${ }^{1} \mathrm{H}-\mathrm{NMR}$ and the purity was analysed by GC.Under the optimum conditions, purity of prenyl alcohol reached $89.07 \%$ and the yield of prenyl alcoholreached $84.39 \%$ from isoprene.

\section{References}

[1] Qin. Guoming, Qin. Jiqiang, Fu. Jiansong, et al. Progress in synthesis and application of Prenyl Alcohol [J]. Petrochemical Technology and Economy, 2010, 26(3): 55-58. (in Chinese)

[2] Cui. Ruping, Lin. Yuehua, Wu. Lu. Preparation of Prenyl Alcohol intermediate of Cyhalothrin [J]. Guangdong Chemical Industry, 2001, 6: 22-23. (in Chinese)

[3] Nian. Baoyi, Chen. Panpan, Lin. Wutao, et al.Synthesis of Citral through hydrolysis of Geranyl Acetone [J]. Journal of Sanming University, 2007, 24(4):411-414. (in Chinese)

[4] Yang. Xin, Jiang. Zitao, Li. Rong, et al. Component analysis and comparison of antioxidant capacity of Lemongrass Essential Oil [J]. Food Science and Technology, 2010, 35(8): 311-316.

[5] Hu. Zuguang, Yin. Zhongzhu, Chen. Shuhua, et al. Impact of Citral to plateletaggregation effect of ratand human [J]. Pharmacology and Clinical of Chinese Traditional Medicine, 1988, 4(1): 16-18.(in Chinese)

[6] Yin. Zhiyong, Wang. Qiujuan, Jia. Ying. Experimental study on the anti-asthma effect of water extract of Citral from Litsea Cubeba[J]. Clinical Pharmacology and Therapeutics in China, 2006, 11(2): 197-201. (in Chinese)

[7] Hierro I, Valero A, Pérez P, et al. Action of different monoterpenic compounds against Anisakis simplex s.l. L3 larvae[J]. Phytomedicine, 2004, 11(1): 77-82.

[8] Zheng. Dagui, Wen. Chenglian. Preparation of Prenyl Alcohol with high purity [J]. Journal of Jiangxi Normal University, 1988, 12(4): 88-90. (in Chinese)

[9] Zhao. Mingjiang, Zhao. Mingjun, Meng. Qinbiao. Method for producing C5 enol from Isoprene and Hydrogen Chloride [P]. CN: 102381940, 2012-03-21. 